Original Contribution

\title{
RODENTICIDAL EFFECTIVENESS OF INDOMETHACIN BAITS IN WARFARIN-RESISTANT ROOF RATS (RATTUS RATTUS) AND HOUSE MICE (MUS MUSCULUS)
}

\author{
G. Zhelev*, K. Koev, Vl. Petrov \\ Department of Veterinary Microbiology, Infectious and Parasitic Diseases, Faculty of Veterinary \\ Medicine, Trakia University, Stara Zagora, Bulgaria
}

\begin{abstract}
Deratisation is one of the basic anti-epidemic measures, directed to protect the health of humans and animals. Nowadays, anticoagulants are still the most commonly used rodenticides. In recent years, the problem of development of resistant synanthropic rodents to these agents is becoming more serious. This is the reason for increasing interest in discovering alternative methods for controlling the resistant populations. It is known that some non-steroidal anti-inflammatory drugs (NSAIDs) act as synergists and significantly increase the toxicity of anticoagulant rodenticides, but convincing information on their effectiveness in anticoagulant-resistant rodents is still missing. The aim of the present research is to contribute to solve this problem, by studying the effectiveness of $0.025 \%$ indomethacin baits, administered alone and combined with warfarin, in warfarin-resistant wild synanthropic rodents. In the conducted laboratory food tests 36 roof rats (Rattus rattus) and 60 house mice (Mus musculus) were included. A very high toxicity of indomethacin baits in resistant rodents, leading up to $100 \%$ mortality, occurring between 24 to 48 hours post acceptance were found. NSAIDs mechanism of action, clinical signs and pathological findings in the intoxicated rodents are discussed. Based on the laboratory conducted tests and scientific data analysis, we conclude that $0.025 \%$ indomethacin baits have high effectiveness in anticoagulant-resistant synanthropic rodents and could be used as an alternative method for control of resistant populations.
\end{abstract}

Key words: indomethacin, rodenticide, anticoagulant resistance, deratisation

\section{INTRODUCTION}

Deratisation is a complex of procedures aimed at reducing the number of harmful rodents, which are in terms connected to high economical loses and thread health of livestock, pets and people. Nowadays, anticoagulant rodenticides are the most common and frequently used approach in deratisational practice (1-2). Building resistance towards this therapeutics in synanthropic rodent is not a new phenomenon and is known since 1958. However, recently the problem increases (3-6). This negative tendency raises the interest in alternative anticoagulant rodenticides and development of new methods for control of the anticoagulantresistant rodents.

*Correspondence to: $G$. Zhelev, Department of Veterinary Microbiology, Infectious and Parasitic Diseases, Faculty of Veterinary Medicine, Trakia University, 6000 Stara Zagora, Bulgaria,

zhelev_vet@abv.bg, +35942699614,+359896976443
In previous studies we have proved anticoagulant resistance among synanthropic rodents in Bulgaria (7). In our country, apart from traps, the only non-anticoagulant treatment registered for use in animal farming, are cellulose-based rodenticides and ultrasonic repellant devices. However, according to latest studies, a low effectiveness of these methods, impotence and insufficiency for use in the deratisational practice was found (8-9).

It is known, that some substances may increase the toxicity of anticoagulants. Many authors prove higher toxicity in rodents of so called "potentiated anticoagulants", containing synergistic substances (e.g. non-steroidal antiinflammatory drugs (NSAIDs), some sulphonamides and antibiotics, vitamin $\mathrm{D}_{3}$ and etc.) (10). The most frequently used drugs potentiating anticoagulant rodenticides are NSAIDs. According to Abatan et al. (11) indomethacin has the highest toxicity to synanthropic rodents among all NSAIDs. It is 
proven that application of indomethacin can lead to development of aplastic anemia. Indomethacin is also hepato- and nephrotoxic, expressed in formation of liver necrosis and rapidly developing acute renal failure (after intake of high doses) or interstitial nephritis (11). NSAIDs' ulcerogenic effect is probably due to the inhibited synthesis of mucopolysaccharides, covering and protecting the gastrointestinal mucosa from the activity of hydrochloric acid and digestive enzymes and also from the inhibited synthesis of some prostaglandins with cytoprotective effect on mucosa. It is proven that most NSAIDs directly damage the gastrointestinal mucosa by causing apoptosis and necrosis of enterocytes $(11,12)$. Kesyakova (13) and Pahwa (14) found that bromadiolone and warfarin baits, potentiated with indomethacin have higher toxicity, and death occurs within shorter period and after consumption of lower dosage, compared to baits without indomethacin.

Despite the proven enhanced toxicity of potentiated anticoagulants to rodents, their effectiveness in anticoagulant-resistant rodents is not sufficiently studied.

The present research aims to clarify this problem by studying the potential of indomethacin baits for control of warfarinresistant synanthropic rodents.

\section{MATERIAL AND METHODS}

Research was conducted on 36 wild roof rats (Rattus rattus) and 60 wild house mice (Mus musculus) caught in livestock farms in the region of Stara Zagora, South Bulgaria.

Rodents were tested in advance for resistance and categorized as warfarin-resistant using
Lethal feeding - period test or Blood clotting response test, in accordance with the recommendations of European and Mediterranean Plant Protection Organization (EPPO) (15). After testing for resistance the rodents were given one month break period, following which were included in feeding (nochoice) tests lasting 21 days in house mice and 28 days in roof rats, followed by 14-days-long monitoring (15-16). Warfarin-resistant roof rats and house mice were then split in 3 groups (equally by both sexes). The first groups were fed $0.025 \%$ warfarin bait, the second $-0.025 \%$ indomethacin bait, and the third $-0.025 \%$ warfarin bait, potentiated with $0.025 \%$ indomethacin. Changes in health condition of the animals, lethality and pathoanatomy were recorded. The groups fed only with $0.025 \%$ warfarin bait were used as a control in the tests and served as a base for interpreting the results.

The statistical data analyses were processed using GraphPad software. Values were expressed as mean \pm standard deviation. Comparison of results between the groups was done using unpaired t-test. Differences were defined as statistically significant in values of $\mathrm{P}<0.05$.

Ethics: The experiments were conducted in strict compliance to regulations for humane treatment of experimental animals in the Republic of Bulgaria and with permission of the institutional Animal Care Committee (№62/14.06.2013).

\section{RESULTS}

The results of the conducted tests are presented in the Table 1.

Table 1. Rodenticide activity of indomethacin and potentiated warfarin baits in warfarin-resistant roof rats (Rattus rattus) and house mice (Mus musculus).

\begin{tabular}{|c|c|c|c|c|c|c|c|c|c|}
\hline \multirow{3}{*}{ Species } & \multirow{3}{*}{ Bait } & & \multirow{3}{*}{$\begin{array}{c}\begin{array}{c}\text { Pre-test period } \\
\text { /3 days/ }\end{array} \\
\mathrm{A}_{1}\end{array}$} & \multicolumn{4}{|c|}{$\begin{array}{l}\text { Test period } \\
\text { /28 days for roof rats; } 21 \text { days for house mice/ }\end{array}$} & \multicolumn{2}{|c|}{ Mortality } \\
\hline & & & & \multirow[b]{2}{*}{$\mathrm{A}_{2}$} & \multirow[t]{2}{*}{ 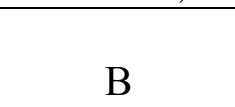 } & \multicolumn{2}{|c|}{$\mathrm{C}$} & & \\
\hline & & & & & & $\mathrm{W}$ & $\mathrm{I}$ & & \\
\hline \multirow{3}{*}{$\begin{array}{l}\text { Rattus } \\
\text { rattus }\end{array}$} & W & 12 & & $1236+17$ & $542.8 \pm 4$ & $64+2$ & & $0 / 12$ & 0 \\
\hline & $\mathrm{I}$ & 12 & 1 & & $3 * \pm 1$ & & $22.8 \pm 3.4$ & $12 / 12$ & 100 \\
\hline & $\mathrm{W}+\mathrm{I}$ & 12 & & & $69.5^{*} \pm 17.6$ & $17.5 \pm$ & $17.5 \pm 4.19$ & $12 / 12$ & 100 \\
\hline \multirow{3}{*}{$\begin{array}{c}\text { Mus } \\
\text { musculus }\end{array}$} & $\mathrm{W}$ & 20 & .4 & $212.1 \pm 77.5$ & $4385.8 \pm 109.5$ & $1096.5 \pm 27.5$ & - & $0 / 20$ & 0 \\
\hline & $\mathrm{I}$ & 20 & $248.2 \pm$ & $152.1 \pm$ & $152.1 * \pm 31.8$ & - & $31.3 \pm$ & $20 / 20$ & 100 \\
\hline & $\mathrm{W}+\mathrm{I}$ & 20 & $215.9 \pm 53.1$ & $163.8 \pm 34.5$ & $163.8^{*} \pm 34.5$ & $40.8 \pm 8.3$ & $40.8 \pm 8.3$ & $20 / 20$ & 100 \\
\hline
\end{tabular}

Legend:

$\mathrm{W}-0.025 \%$ warfarin; $\mathrm{I}-0.025 \%$ indomethacin; $\mathrm{A}_{1,2}$ - average daily consumption of bait $\left(\mathrm{g} \mathrm{kg}^{-1}, \pm \mathrm{SD}\right)$; $\mathrm{B}$ average cumulative consumption of bait within the whole test period $\left(\mathrm{g} \mathrm{kg}^{-1}, \pm \mathrm{SD}\right)$; $\mathrm{C}$ - average cumulative intake of active ingredient for the whole period $\left(\mathrm{mg} \mathrm{kg}^{-1}, \pm \mathrm{SD}\right) ; *^{-}$bait is consumed only within the first 24 hours of the test period. 
In the groups fed only with $0.025 \%$ warfarin bait, during the test and monitoring period, no signs of deviation in health status of the

rodents and in lethality were found. The average cumulative intake of warfarin in survival roof rats was $886.4 \mathrm{mg} \mathrm{kg}^{-1}$, and in house mice $1096.5 \mathrm{mg} \mathrm{kg}^{-1}$. High values of rodenticide taken in are indicative of a present form of high-level-resistance.

In the groups fed only with $0.025 \%$ indomethacin bait, consumption was found to be exclusively within the first 24 hours of the experiment. Change in health status of test animals was found 12 hours from the begging of the experiment and expressed in inappetence, depression and reduced activity. The rodents moved reluctantly and their movements being slow and stiff. Signs of anemia were expressed in nose and paws. In some rodents trembling of forelimbs and head was found. In time the clinical signs described intensified, and a few hours before death signs of severe respiratory distress were present breathing was bradypnoeic with increased amplitude, and cyanotic colour of nose and paws. In all animals 100\% lethality was found, occurring within 24 to 48 hours from the beginning of the experiment. During pathoanatomical examination presence of bloody liquid in the peritoneal cavity and haemorrhages on mucosa of stomach and intestines was found. In roof rats average cumulative intake of indomethacin was 22.8 $\mathrm{mg} \mathrm{kg}{ }^{-1}$, and in house mice $31.3 \mathrm{mg} \mathrm{kg}^{-1}$.

Absolutely identical was the situation in groups fed with potentiated warfarin bait. In roof rats the average cumulative intake of warfarin and indomethacin was $17.5 \mathrm{mg} \mathrm{kg}^{-1}$, and in house mice $-40.8 \mathrm{mg} \mathrm{kg}^{-1}$.

\section{DISCUSSION}

The results of the conducted tests demonstrated a very high toxicity of indomethacincontaining baits $\left(250 \mathrm{mg} \mathrm{kg}^{-1}\right)$ in warfarinresistant roof rats and house mice. Between groups fed $0.025 \%$ warfarin bait, potentiated with $0.025 \%$ indomethacin and those groups fed only $0.025 \%$ indomethacin bait, no statistically significant differences $(\mathrm{P}>0.05)$ supporting the first groups were found in the measured indexes, so no potentiating effect of indomethacin to warfarin was established. As a result of this, we consider that the mortality and the inspected signs of intoxication in these categories of rodents (warfarin-resistant roof rats and house mice) are contributed only to the effect of indomethacin. Supporting this thesis are the result of Maitai and Muneng
(17), who fed house mice for 12 hours with indomethacin food baits, containing variable concentration of indomethacin - between 0.0125 and $1.0 \%$. They found $100 \%$ mortality in groups fed baits with indomethacin concentration above $0.0625 \%$, and death in all animals occurred within 24 to 72 hours. The same authors repeated the experiments with laboratory brown rats (Rattus norvegicus) and found similar results, but death in some animals occurred later - up to the 6th day following intake. Abatan et al. (11) also conducted laboratory experiments with brown rats, in which using a gastric tube, they applied NSAIDs - indomethacin $\left(5 \mathrm{mg} \mathrm{kg}^{-1}\right)$, piroxicam (15 $\left.\mathrm{mg} \mathrm{kg}^{-1}\right)$, aspirin $(20 \mathrm{mg} \mathrm{kg}$ ) and phenylbuthazone $\left(10 \mathrm{mg} \mathrm{kg}^{-1}\right)$. Clinical signs as anorexia, depression, low activity, diarrhoea and death are observed only in the indomethacin-treated group. In the same group they found also the most severely expressed biochemical, haematological, and pathohistological changes. Similar results are reached by Taiwo and Conteh (12), who conducted laboratory tests on brown rats and house mice, in which they applied a single dose of indomethacin orally. Rodents were divided in several groups and received different doses of indomethacin $-83 \mathrm{mg} \mathrm{kg}^{-1}$, $166 \mathrm{mg} \mathrm{kg}^{-1}$ and $250 \mathrm{mg} \mathrm{kg}$. They found $100 \%$ lethality in the experimental animals from all groups within 36 to 82 hours. Based on the results gathered, they calculated $\mathrm{LD}_{50}$ of indomethacin in brown rats $21.5 \mathrm{mg} \mathrm{kg}^{-1}$, and in house mice $15 \mathrm{mg} \mathrm{kg}^{-1}$, but according to Omogbai et al. (18) the values for brown rats are lower $-12.5 \pm 1.5 \mathrm{mg} \mathrm{kg}^{-1}$.

The examples given prove that monotreatment with indomethacin in synanthropic rodents, without anticoagulants, is sufficient to cause severe intoxication and death. It is known that NSAIDs express a toxicity of different level in certain animal species. Indomethacin and its metabolites have highly irritating effect on gastrointestinal tract and ulcerogenic sequel, and frequency and severity of damages depend on the amount of indomethacin excreted with bile, which is different for every animal species. The higher bile excretion in rodents is considered as one of the main reasons for its high toxicity in synanthropic rodents $(11,17)$.

In our experiments in all rodent groups receiving indomethacin baits, the earliest clinical sign of intoxication was anorexia consumption of bait was found only within the first 24 hours of the test. Similar are the observations of Abatan et al. (11), Maitai \& Muneng (17) and Taiwo \& Conteh (12), who found anorexia immediately after 
indomethacin intake and claim doubt that it is probably caused by its irritating effect on the gastrointestinal tract.

In experiments of Maitai \& Muneng (17) rodents died with signs of severe haemorrhages in gastrointestinal tract, on the background of severe disturbance in coagulation. The coagulation time before death was over 30 minutes, while at the beginning of the test was in 10-15 seconds range. Clinical signs expressed in depression and anorexia, and macroscopical pathomorphological changes in mice included severe haemorrhages in gastrointestinal tract and bloody liquid present in the peritoneal cavity. Taiwo \& Conteh (12) observed anorexia, weakness and dehydration in the intoxicated rodents, which distinctly intensified in time. In $43.8 \%$ of rats they found diarrhoea and bilateral haemorrhages in the medial canthus of the eye. Pathomorphological lesions included congestion, haemorrhages and focal ulcerations on the gastrointestinal mucosa, as well as pale foci on liver.

In our experiments all groups of rodents, which consumed indomethacin baits, had similar to the aforestated signs. In comparison with the changes observed by Taiwo \& Conteh (12) in our experiment presence of diarrhoea and bilateral haemorrhages in the medial canthus of eye was not found. Also no signs of changes in blood coagulation, as well as hemorrhages outside the gastrointestinal tract, contrary to those found by Maitai \& Muneng (17). The reason for the incongruity observed perhaps is due to differences in species of the synanthropic rodents used in the tests, as well as the fact that our studies are conducted on anticoagulant-resistant specimens.

In comparison with anticoagulant rodenticides, in which mortality in rodents occurs 2-5 to 1012 days after consumption (10,13), indomethacin baits cause death in synanthropic rodents within significantly shorter period -24 to 48 hours. This is a major advantage, which makes them an appropriate choice for deratisation in sites of contagious diseases outbreaks, where important are quick elimination of the synanthropic rodents and to hastily exclude them as a source of infection and spreading factors. Likewise when compared with the effect of classic acute rodenticides (e.g., zinc phosphide) another of their advantages stands out. Classic acute rodenticides lead to fast mortality within 1 to 4 hours following consumption, death is preceded by agonal phase, concurrent with emitted ultrasounds, signals for disaster, based on which the other specimens in the population build a behavioural reaction to evade the rodenticidal baits, known as "aversion" or "bait shyness" $(10,13)$. On the contrary, death after consumption of indomethacin occurs significantly later - after 24 hours or more, and is not accompanied with agonal reaction, based on which built aversion in other members of the population is not expected. This way the attractiveness and sufficient intake of baits is kept, which makes possible the complete abolishment of the population.

Concerning the effectiveness of the indomethacin baits in practice, Abatan et al. (11) and Maitai \& Muneng (17) inform that in many West African countries indomethacin is traditionally used in the fight against rodents and with very good results, but their use is not officially reglamented and they are not patented as rodenticidal products. They emphasize that indomethacin baits are cheaper, more affordable and safer in comparison with other rodenticides, (e.g., zinc phosphide and brodifacum). This fact and their highly rodenticidal effect in anticoagulant-resistant rodents, found in our experiments, make them an appropriate drug in control of the resistant populations. We think that studies in this aspect should continue with the aim to introduce indomethacin baits in the deratisation practice.

\section{REFERENCES}

1. Hadler, M., Buckle, A., Forty five years of anticoagulant rodenticides - past, present and future trends. Proceeding of the $15^{\text {th }}$ Vertebrate Pest Conference. Newport Beach, California, USA, pp. 149-155, 1992.

2. Mihajlova, A., Georgieva, T., Dimitrova, $\mathrm{N}$., List of drugs reglamented for use in disinfection, disinsection and deratisation in Republic of Bulgaria (2001-2003). Ministry of Health, Sofia, Bulgaria, pp. 181 $-189,2001$.

3. Boyle, C.,M., Case of apparent resistance of Rattus norvegicus Berkenhout to anticoagulant poisons. Nature, 188: $517-$ 525,1960 .

4. Lund, M., Resistance to second-generation anticoagulant rodenticides. Proceeding of the $11^{\text {th }}$ Vertebrate Pest Conference. Sacramento, California, USA, pp. 89-94, 1984.

5. Myllymäki, A., Anticoagulant resistance in Europe: appraisal of the data from the 1992 EPPO questionnaire. Pestic Sci, 43: 69-72, 1995.

6. Pelz, H.-J., Spread of resistance to anticoagulant rodenticides in Germany. Int J Pest Manage, , 53 (4): 299-302, 2007. 
7. Zhelev, G., Lyutskanov, M., Petrov, V., Michaylov, G., Marutsov, P., Koev, K., Tsvetanov, T., Investigations on the warfarin resistance of synanthropic rodents. Bulg J Vet Med, 16 (Suppl. 1): 141 - 146, 2013.

8. Zhelev, G., Lyutskanov, M., Petrov, V., Michaylov, G., Marutsov, P., Koev, K., Tsvetanov, T., Efficacy of a cellulose-based rodenticide for control of warfarin-resistant black rats (Rattus rattus). Bulg $J$ Vet Med, 16 (Suppl. 1): 134 - 140, 2013.

9. Zhelev, G., Koev, K., Marutsov, P., Mihaylov, G., Petrov ,V., A study on the effectiveness of combined electronic devices to repel rodents. Proceeding of the International scientific conference "Veterinary Medicine - Science, Practice, Business". Stara Zagora, Bulgaria. Bulg J Vet Med, 17 (Suppl. 1, Abstracts book ): 7374, 2014.

10.Kesyakova, S., Kremenski, M., Studies on the potentiating effect of some drugs on deratisational activity of bromadiolone (Lanirat). Vet. Medicine (BG), I, 3: 202204, 1995.

11.Abatan, M.O., Lateefand, I., Taiwo, V.O., Toxic Effects of Non-Steroidal AntiInflammatory Agents in Rats. Afr J Biomed Res, 9: 219 - 223, 2006.

12. Taiwo, V.O., Conteh ,O.L., The rodenticidal effect of indomethacin:
ZHELEV G., et al. pathogenesis and pathology. Vet Arhiv, 78, 167-178, 2008.

13. Kesyakova, S., Potentiated anticoagulants appropriate drugs for deratisation of livestock sites with epizootologic issues. DDD Bulletin (BG), 3-4: 59-62, 2001.

14.Pahwa, R., Warfarin toxicity augmentors indomethacin and atromid-S, laboratory studies in the black rat, Rattus rattus Linn. Z. Angew. Zool., 76 (2): 189-194,1989.

15.OEPP/EPPO, Efficacy evaluation of rodenticides: PP 1/198(1) "Testing rodents for resistance to anticoagulant rodenticides". European and Mediterranean Plant Protection Organization, Paris, pp.6571, 1995.

16. Technical notes for guidance in support of Annex VI of Directive 98/8/ec of the European Parliament and the Council concerning the placing of biocidal products on the market 2009. In: Technical notes for guidance on product evaluation Appendices to Chapter 7 Product Type 14 Efficacy Evaluation of Rodenticidal Biocidal Products.

17.Maitai, C.K., Munenge, R.W., New use of indomethacin. East Cent. Afr. J. Pharm. Sci., 14: 12-15,2011.

18.Omogbai, E.K., Ozolua, R.I., Idaewor, P.E., Isah, A.O., Some studies on the rodenticidal action of indomethacin. Drug Chem Toxicol, 22: 629-642, 1999. 